NBER WORKING PAPER SERIES

\title{
CHOICE UNDER UNCERTAINTY: A MODEL OF APPLICATIONS FOR THE SOCIAL SECURITY DISABILITY INSURANCE PROGRAM
}

\author{
Janice Halpern \\ Jerry Hausman \\ Working Paper No. 1690 \\ NATIONAL BUREAU OF ECONOMIC RESEARCH \\ 1050 Massachusetts Avenue \\ Cambridge, MA 02138 \\ August 1985
}

The Department of Health and Human Services has financed this research through a grant to the Brookings Institution. Hausman also thanks the NSF for research support. John Bound and Lynn Pacquette provided outstanding research assistance. We thank Jim Poterba for his comments. Helpful suggestions were also made by seminar participants at LSE, M.I.T., and 0xford. The research reported here is part of the NBER's research program in Labor Studies and project in Government Budget. Any opinions expressed are those of the authors and not those of the National Bureau of Economic Research. 
Choice Under Uncertainty: A Model of

Applications for the Social security

Disability Insurance Program

\section{ABSTRACT}

Not all people with health problems are disabled. Some individuals with severe physical or mental impairments, such as blindness or limb amputation, continue to hold jobs and generally function satisfactorily. They constitute, however, a group of potentially disabled individuals who might apply and qualify for Disability Insurance or other disability-related benefits if they were to lose their jobs or to decide that employment offered an inadequate financial or non-pecuniary reward. Thus, disability, or a health-related inability to work, is more than a medical problem but involves motivational and attitudinal factors.

We specify a model of the application process, which we model as choice under uncertainty about approval of an application for Disability Insurance. We specify the possible outcomes to the choice process of an individual in which the probability of acceptance for Disability Insurance is a key consideration. We then estimate a joint model of labor supply and application to the Disability Insurance program based on the 1972 survey. We then compare our results to the observed time series applications process since 1976. Lastly, we estimate the sensitivity of the application process to the probability of acceptance and the level of benefits.

Janice Halpern

Lexecon

140 South Dearborn

Chicago, IL 60603
Jerry Hausman

Department of Economics

M.I.T., E52-271A

Cambridge, MA 02139 
1. The Disability Insurance (DI) Program and The Disabled Fopulation

Not all people with nealth problems are disabled. Some individuals with severe physical or mental impairments, such as blindness or limb amputation, continue to hold jobs and generally function satisfactorily. They

constitute, however, a group of potentially disabled individuals who might apply and qualify for DI or other disability-related benefits if they were to lose their jobs or decide that employment offered an inadequate financial or non-pecuniary reward. Thus, disability, or a health-related inability to work, is more than a medical problem but involves motivational and attitudinal factors.

The DI program does not pay benefits to all the disabled or even to all the severely disabled. Evidence from the 1972 Survey of Disabled and Nondisabled Adults (SDNA) indicated that although 7.7 million adults between the ages of 20 and 64 claimed they were either unable to work at all or unable to work regularly, only 2 million disabled workers were receiving DI benefits in that year. Therefore, 5.7 million adults who considered themselves severely disabled were not receiving benefits under this program. In part this was due to a surprising lack of awareness of the existence of the DI program, even among those who are eligible for benefits, but mostly it is attributable to: the program's strict eligibility requirements. Although critics attributed much of the tremendous growth in the number of beneficiaries up through the end of the $1970^{\prime}$ s to a weakening of administrative standards, the program is still an extremely selective one, fulfilling its original intention of providing benefits only to those with solid work records and severe mental or physical impairments.

Protection against disability was not incorporated into the Social Security program until 1957. The initial DI program provided monthly cash 
benefits only to disabled workers aged 50 to 64 and disabled dependent children of insured workers aged 18 and over disabled before age 18 who were unable "to engage in any substantial gainful activity by reason of any medically determinable physical or mental impairment which can be expected to result in death or to be of long-continued and indefinite duration." State agencies made disability determinations and do so today. Under the DI program today, a totally disabled individual between the ages of 18 and 65 with a sufficient number of quarters of coverage ${ }^{1}$ is eligible, after a five-month waiting period, for the same monthly benefits payable to a retired worker who began receiving benefits at age 65 (known as the primary insurance amount).2 Prior to 1980 individuals who applied and were accepted to the DI program generally continued receiving benefits up to age 65 . The frequency of terminations was quite low apart from natural causes. Under the current administration the frequency of terminations has risen markedly. This policy is currently undergoing both judicial and legislative review. 3

Between 1967 and 1979, a period during which no major legislative changes took place, the number of individuals receiving monthly DI benefits

1. To be eligible for benefits, a person has to have earned at least $\$ 50$ in covered employment in 20 of the last 40 quarters, including the quarters of disability. In addition he has to be fully insured. This means that he needs coverage in half the quarters since 1950 (or the age of 21) with quarters earned before 1951 (or the age of 21).

2. Those eligible as dependents under OASDI are wives and dependent husbands who have reached retirement age, unmarried dependent children (including sons or daughters disabled in childhood), and wives who have entitled children in their care. Maximum limits were put on disability payments with respect to the PIA by legislation, see the Social Security Bulletin, 44, 1981, pp.1431 .

3. The current situation (1985) has evolved once more so that the Administration has agreed to halt widescale terminations and to readmit many individuals who had been terminated from the DI program in the past five years. A class action lawsuit for terminated individuals against the U.S. Government is currently in the Federal court system awaiting judicial action. 
increased from 2.1 to 4.8 million. Uver the same period, total monthly benefits paid increased by a factor of 7.4 , from $\$ 148$ million to $\$ 1.1$ billion. The number of people receiving benefits through a program such as social security disability insurance can expand as the result of an increase in the number of people applying for benefits, an increase in the percentage of applicants granted eligibility status, or a decrease in the number of people who terminate beneficiary status. Considerable evidence indicates that the dramatic expansion in the DI program that took place between 1969 and 1976 is attributable principally to the first and third of these factors. The annual number of disability applications increased from about 9 per 1,000 insured workers in 1963 to a peak of 16 per 1,000 insured workers in 1974 . In 1976, the rate of application was still about 14 per 1,000. During the same time period there was no evidence of any increase in the percentage of applicants who were eventually awaraed benefits. Over the 1963 to 1976 period, this percentage actually decreased slightly, from 49 to 45 percent, although it fluctuated considerably from year-to-year. The termination rate did decline considerably mainly due to the decline in the death rate of the DI beneficiary population.

Since 1976, a marked change has occured in the DI program. The number of persons receiving DI benefits increased from 4.4 million in 1975 to 4.9 million in 1978, but the number of beneficiaries fell to 4.5 million in 1981 . By October 1984 the number of beneficiaries stood at 3.8 million. 1 The number of monthly benefits awarded to disabled workers fell off sharply from its peak of 592,000 to a low of 298,000 in 1982. These trends are shown in Table A. A very important factor in this decline in awards is that the number of initial allowances upon application fell from about $40 \%$ in 1975 to

1. These data are from the Social Security Bulletin, 48, March 1985, p. 44. 


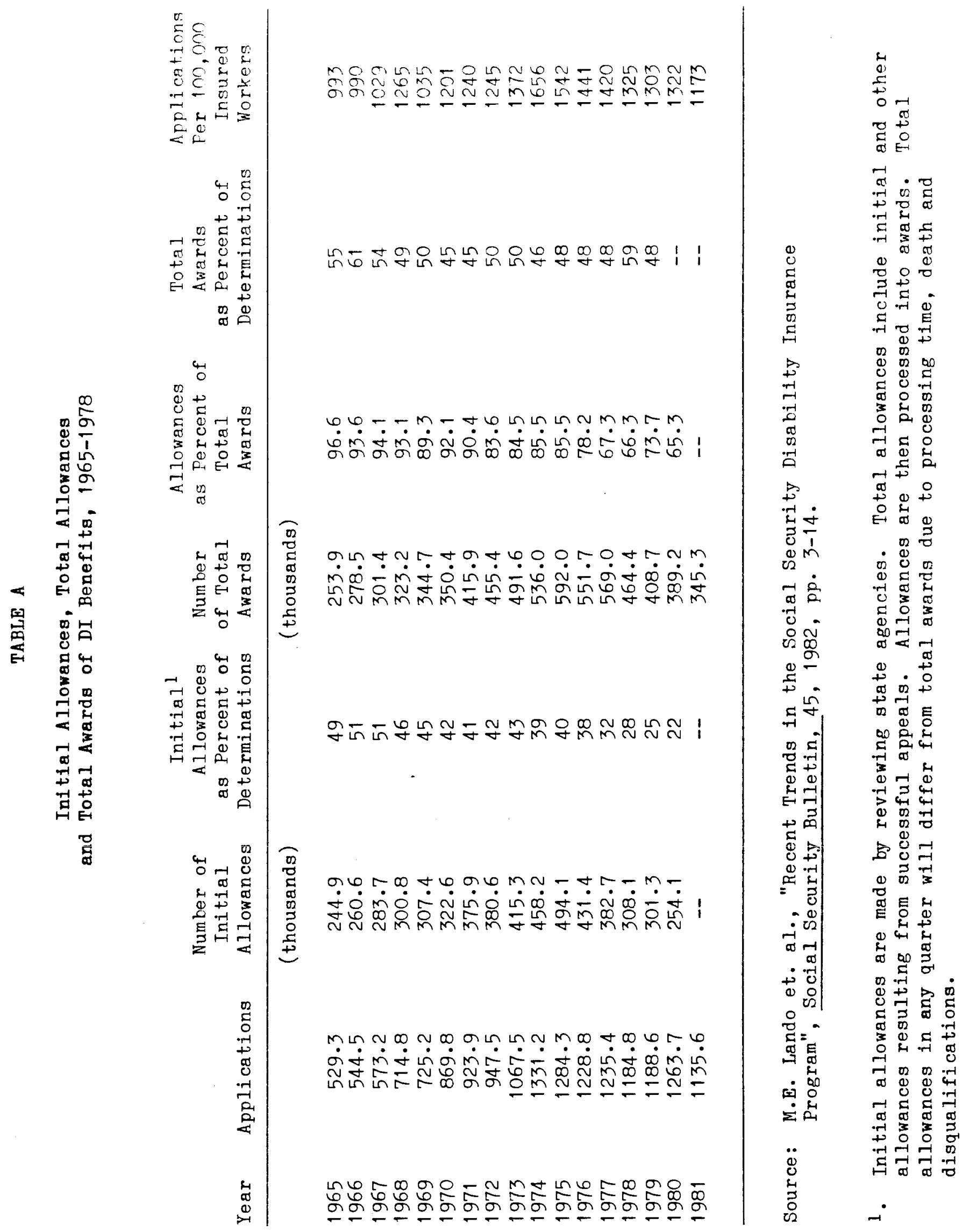


about $22 \%$ in 1980. The percentage had been as high as 51 in in 1967. A discussion of possible reasons for the very rapid decrease in the percentage of initial allowances can be found in Lando et. al. (1982).

Not surprisingly, the large increase in the percentage of applicants denied has led to increases in the number of appeals. ${ }^{1}$ A reconsideration can be asked for at the state level and then a hearing can be called for by an Administrative Law Judge (ALJ). Nevertheless, the percentage of reversals at the reconsideration level decreased sharply also between 1975 and 1980. The drop between 1970 and 1980 was 58\% which exceeds the decrease in the initial allowance rate. However, at the ALJ level the number of hearings increased from 78\% from 1975 to 1980 . The reversal rate also increased at this level from $48 \%$ in 1975 to $58 \%$ in 1980 . While it is difficult to calculate precisely the final deposition by year of initial application, a calculation can be made at the year of final disposition of the application. In 1970, $48 \%$ of final dispositions were favorable. In 1975 this percentage rose to almost 50\%. In 1980 only $34 \%$ of final determinations were favorable. Therefore, the probability of a successful application for DI has decreased sharply over the past few years, even when all levels of appeal are accounted for.

We now focus on an important factor in the determination of the number of DI beneficiaries. Many models estimated on time series data have attempted to explain the level of applications in terms of benefit levels, unemployment rates, and other macroeconomic variables. A review of these models is contained in Halpern (1981). However, consideration of the last column in Table 1 demonstrates that while a decrease in applications per 1000

1. The administrative process of the DI program is well described in Mashaw (1983). 
workers of $29 \%$ has taken place since the peak year of 1974 , that the aecrease has been $19 \%$ from the more normal economic year of 1976 . Over that same period the number of applications has falien by only $7.6 \%$. Because disability rises with age the appropriate comparison figure probably lies somewhere between $8 \%$ and $19 \%$, but the relatively small decrease in applications may be somewhat surprising given the sharply decreased probability of receiving DI. Also, the greater proportion of initial denials means that applicants will have to remain out of the labor force as their case is being decided through the reconsideration and appeals process. Therefore, the main reason for the substantial decrease in new DI beneficiaries comes from the acceptance rate, not from the applications rate. This paper builds a model of the application process on cross section data from a 1972 survey, but our results seem to agree well with the observed times series experience. That is, our results indicate that the probability of acceptance has a significant, but not a particularly large effect, on the probability of application. Potential applicants seem more sensitive to the benefit level than to the probability of acceptance.

In the rext section, we specify a model of the application process; which we model as choice under uncertainty about approval of an application for DI. We specify the possible outcomes to the choice process of an individual in which the probability of acceptance for DI is a key consideration. In Section 3, we estimate a joint model of labor supply and application to the DI program based on the 1972 survey. We then compare our results to the observed time series applications process since 1976 . Lastly, we estimate the sensitivity of the application process to the probability of acceptance and the level of benefits. 
2. An Empirical Nodel of Disability Insurance Application

In this section, we develop an econometric model of the choice to apply

for Disability Insurance (DI). The basis of this empirical development is the hypothesis that by specifying the available options and examining the choices disabled individuals made, the factors that influence their decisions can be determined and their relative contributions evaluated. Since the choice involves certain outcomes, in particular whether the application for DI will be approved, a model of choice under uncertainty is required. We apply the Von Neumann-Morgenstern approach to choice under uncertainty in the development of the model. 1

Of course, this study is not the first to look at the DI application and labor force participation decisions of disabled individuals. The earlier literature concentrated on showing that health was an important explanatory variable in labor supply models and that dummy variable representations of an individual's eligibility for DI benefits also significantly improved the fit of a labor supply equation. Later literature tried to measure more directly the factors that were relevant in an individual's decision about whether to apply for DI -- factors such as the size of the benefit which he would receive if eligible and the wage he can earn if he works. While it has been successfully demonstrated that health is an important factor in the work vs. DI application decision of impaired individuals, failure to develop and empirically implement a structural model of utility-maximizing income choice

1. Considerable controversy continues to exist over the positive value of the Von Neuman-Morgenstern approach as a description of individual behavior under uncertainty. A recent review is given by Machina (1983). 
has left the role that the II prograr parameters play in influencing this choice of unanswered question. We attempt to specify and estimate a structural modeI. 1

In order to make the problem tractable, the lifetime utility maximizing framework will be considerably simplified.2 The discussion below is based on a two-period framework in which an impaired worker decides whether to apply for DI benefits for next period by comparing his expected utility from working and from applying for (but not necessarily receiving) DI benefits. Of course, some individuals may be so severely disabled that they are unable to work. But, the overwhelming majority of disabled individuals do work. We take account of the severity of the individual disability both in the labor supply decision and in the probability of acceptance to DI model.

The basis of the empirical analysis is a two-period utility maximization problem in which an individual decides in period $t$ whether or not to apply for DI which will be received in period $t+1$. Igmoring the DI program to begin with, let $x$ be the total vector of goods from which an individual can choose and assume all goods except hours of work $h$, can be aggregated into a single consumption good, $c$, with price normalized to one. The consumer's problem is to maximize a direct utility function $u(c, h)$ subject to the constraint that $c \leqslant w h+y$, where $h$ is hours of work, w is the net (of tax) wage rate, and $\mathrm{y}$ is exogenous non-labor income (virtual income with taxes). The additional complication exists that because of the progressive federal income tax and the structure of many income support programs (such as AFDC and social security retirement), both the net wage and non-labor income

1. A review of the literature up to 1981 is given by Halpern (1981). A recent paper is Havemann and Wolfe (1984). They estimate a reduced form model which takes account of other transfer programs in addition to DI. 2. See Halpern (1981) for a theoretical treatment of the lifetime utility maximizing problem. 
are functions of the number of hours worked. However, both of these variables will be assumed initially to be constants independent of $h$.

The indirect utility function is the maximum utility attainable as a function of exogenous variables $w$ and $y$ :

$$
\mathrm{V}(\mathrm{w}, \mathrm{y})=\max (U(\mathrm{c}, \mathrm{h}): c \leqslant w h+\mathrm{y}) \text {. }
$$

Assuming the consumer does no saving, all income is consumed and the maximization problem is a matter of choosing $h$.

The effect of the DI program on the budget constraint faced by a utility maximizer will now be considered. Because of the program, the budget line an individual will face in period $t+1$ has three segments that depend on whether he applies for (in period $t$ ) and does or does not receive (in period $t+1$ ) DI benefits.' Let $B$ equal non-DI non-labor income and SSB equal the value of the $D I$ benefits an individual would receive if he applied to the program and his application were accepted. \{See Figure 1\}. Then, if he does not apply for DI benefits, he will maximize utility along budget segment BA corresponding to a constant wage rate $w_{\mathbb{N}^{*}}$. If his application for benefits is rejected, he will have unearned income of $B$ and will face a net market wage of $w_{A}<w_{N}$ and achieve a utility maximum on segment $B C$. His wage if rejected, ${ }^{\mathrm{A}}$, is less than $\mathrm{w}_{\mathrm{N}}$.

There are several reasons to assume that a rejected DI applicant will earn less than a non-applicant with identical personal and socioeconomic characteristics. In order to apply, he must be out of the labor market for five months and can then anticipate an average application processing time of three months. The individual is generally out of the labor force for approximately 1 year. If he should initially be rejected, appeal and then

\footnotetext{
1. For now we do not include income taxes in the model so that the effect of the DI program on choice can be emphasized. However, we do include income taxation in the model subsequently.
} 


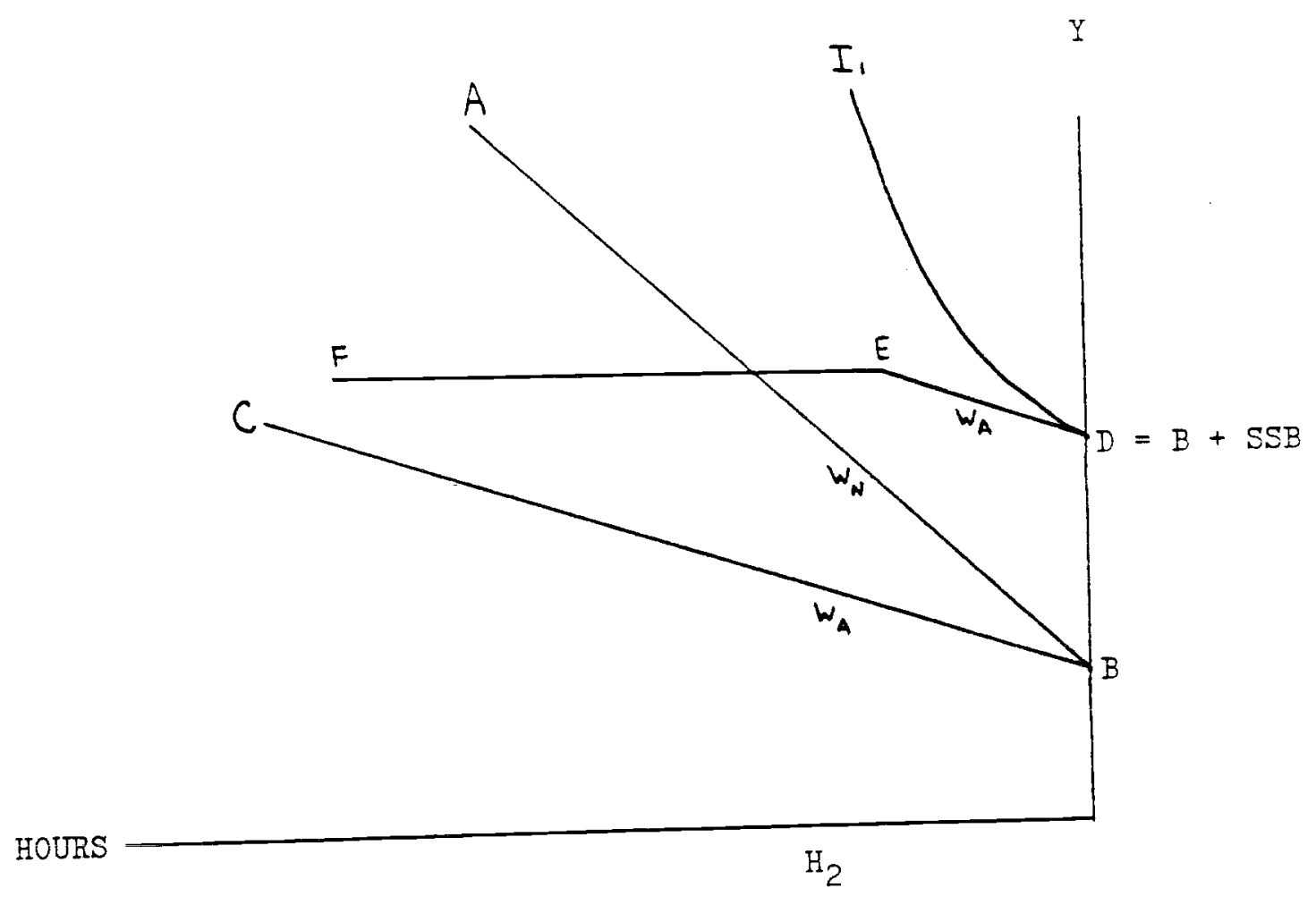

Figure 1. Budget Constraint with a DI Program. 
have his appeal rejected, he would be out of the labor force considerably longer. Several reasons exist to expect that a rejected applicgnt would also re-enter the labor market at a lower wage than he would have received if his labor market participation has been interrupted. First, because his human capital may erode during the time it takes to process his application and his lack of recent experience may lower his productivity, his marginl product will be lower. Secondly, employers may view his being out of the labor force as an indication that his health interfers with his ability to work and consequently may fear that poor health could force him to quit in the future. Furthermore, insurance and pension costs may rise if this event occurs. Third, a period of time spent out of the labor force may be viewed as an indication that the worker has only a weak labor force attachment, i.e., that he is undependable and it is probable that he will soon leave his job. These last factors meant that the wage the employer offers will be discounted for a risk factor and thus may be lower than the value of his marginal product.

If the individual applies and is accepted for DI benefits his unearned income will be B+SSB. Under current program regulations during our data period, he is allowed to earn up to $\$ 50$ a month without penalty (corresponding to $\mathrm{H}_{2}$ hours of work at wage $\mathrm{w}_{\mathrm{A}}$ in Figure 1 ). If he earns more than $\$ 50$ his benefits are not immediately terminated but he is considered to be engaged in a trial work period which may lead to termination for recovery in future months. Because the form of benefit reduction rule imposed on DI recipients is not easily diagrammed, the assumption is made that the "implicit" penalty of potentially losing benefits is so great that his wage is effectively zero for earnings above $\$ 50$. Thus, his total budget constraint is DEF. In the figure, maximization occurs at $h=0$ on indifference curve $I_{1}$. 
Assume that the indiviaual $i$ is working in period $t$ and is deciding whetris, to work in period $t+1$ or apply for DI benefits which would be received in period $t+1$. Let $a_{i}$ index the severity of the individual's disability. The time subscript will be suspended unless necessary for clarity). This index obviously includes a measure of physical and mental health and functional ability, and may also include vocational factors such as age and prospects for retraining which are taken into account in determining eligibility for DI benefits. Based on this index, the individual faces a probability $p\left(d_{i}\right)$ that if he applies for DI benefits his application will be accepted and he will achieve a utility maximum on segment DEF rather than BC. His problem, under the Von Neumann-Morgenstern framework then, is to maximize his expected utility in period $t+1$ by choosing whether or not to apply for DI benefits. 1

An individual will apply for DI benefits if his expected utility from applying is higher than his known utility if he does not apply, assuming no aiscrepancy between desired and actual hours of work. If he decides not to epply, he will choose hours of work $h=h *$ determined by Roy's identity $\mathrm{h}^{*}=\mathrm{V}_{\mathrm{w}} / \mathrm{v}_{\mathrm{y}}$, which corresponds to the value of his indirect utility function, $V\left(w_{N}, B\right)=V_{1}$. If he does apply for $D I$ benefits, the probability is $p\left(d_{i}\right)$ that his application will be accepted and that as a result he will achieve utility level $V^{\prime}\left(w_{A}, B+S S B\right)=V_{2}$, where $V^{\prime}()$ differs from $V()$ in that a DI recipient's hours are constrained to be less than or equal to $\$ 50 / \mathrm{w}_{\mathrm{A}}$. In Figure 1, utility maximization occurs with $\mathrm{h}=0$, although different utility functions could lead to maximization anywhere on segment DE. The contention that $w_{A}<w_{N}$ means that applying for $D I$ benefits is not

1. We also attempted, unsuccessfully, to include costs to the individual apart from his lower wage from the time he spends waiting for the decision on his acceptance to DI. This additional development is hampered by the lack of information about state benefits that an individual receives during the waiting period. 
costless and is important to the model since otnerwise almost everyone with $p\left(d_{i}\right)>0$ who could reach a higher level of utility on $D E$ than BA would apply for benefits. If the individual's application for benefits is rejected, and the probability is $\left(1-p\left(d_{i}\right)\right)$ that this will occur, he will have non-labor income $B$ and will face a market wage of $\mathrm{w}_{A}$. He will choose to work $h=h^{* *}$ hours and the corresponding value of his indirect utility function will be $\mathrm{V}\left(\mathrm{w}_{\mathrm{A}}, \mathrm{B}\right)=\mathrm{V}_{3}$. Therefore, according to expected utility theory the individual's expected utility if he applies to the DI program is $V=p\left(d_{i}\right) V_{2}$ $+\left(1-p\left(d_{i}\right)\right) V_{3}$. If $V>V_{1}$ he will apply for benefits, while if $V<V_{1}$ he will decide not to apply.

Since empirical models of individual choice under uncertainty are extremely rare in the multigood case, we decided to take a common labor supply model and expand it to model the choice under uncertainty. We begin with the linear labor supply function for desired hours for individual i

$$
\text { (2) } h_{i}^{*}=\delta y_{i}+\alpha w_{i}+z_{i} \gamma
$$

where $y_{i}$ is non-labor income, $w_{i}$ is the wage, and $z_{i}$ are socioeconomic variables. Either the indirect or the direct utility function is required here. The integration of equation (2) to recover the indirect utility function now must take explicit account of the constant of integration because the cardinality of the utility function has a crucial role in the theory of the choice under uncertainty. 1 our particular choice of the constant of integration leads to the indirect utility function

$$
\text { (3) }\left\{-e^{\delta w_{i}}\left(y_{i}+\frac{\alpha w_{i}}{\delta}-\frac{\alpha}{\delta^{2}}+\frac{z_{i} \gamma}{\delta}\right)\right\}-\theta / \theta=-v^{-\theta} / \theta, \theta<-1
$$

\footnotetext{
1. The importance of the cardinality of the utility function thus differs from previous applications of this methodology, e.g. Hausman $(1981 a, c)$.
} 
where $\theta=-1$ denotes risk neutrality and $-\theta-1$ may be interpreted as the coefficient of relative risk aversion. Similarly, the direct utility function, which is used at kink points and at zero hours of work, is calculated to be at hours of work $H_{i}$ and consumption $x_{i}=y_{i}+w_{i} H_{i}$ calculated to be at hours of work $H_{i}$ and consumption $x_{i}=y_{i}+w_{i} H_{i}$

$$
\left[-\left(\frac{\delta H_{i}-\alpha}{\delta^{2}}\right) e^{-\left[1+\left(\delta x_{i}+Z_{i} \gamma-\alpha / \delta\right) /\left(\alpha / \delta-H_{i}\right)\right]}\right]^{-\theta} / \theta=-U^{-\theta} / \theta
$$

In our first model which does not include taxes three possible outcomes are possible. If the first action is taken and the individual does not apply for DI his indirect utility is determined by his non-labor income $\mathrm{y}_{\mathrm{n}}$ and his market wage $w_{n}$ from equation $(3),-V\left(w_{n}, y_{n}\right)^{-\theta} / \theta=-v_{n}^{-\theta} / \theta .{ }^{2}$ The second possible action for the individual is to apply for DI. One of two uncertain outcomes will then occur. If he is accepted, his utility from equation (4) is

(5) $-U_{0}^{\theta} / \theta=\left[-\frac{\alpha}{\delta^{2}} e^{\left.-\left(\delta^{2} y_{0}+\delta z \gamma\right) / \alpha\right]^{-\theta} / \theta}\right.$

where $y_{0}=y_{n}+S S B$, the sum of non-labor income plus social security benefits. We have assumed that the individual does not plan to work if he is accepted for DI. The other possible outcome is that the individual will be rejected for DI if he applies. His market wage will be $w_{A}<w_{N}$ and his

I. In the multigood case, the Pratt-Arrow measures of relative and absolute risk aversion are not as easily interpretable as in the single good case. Here we are using the terminology with respect to units of utility (utils), given the cardinality of our utility function. We also estimated the constant absolute risk aversion type specification of equation (3). The results are quite similar to the results for the relative risk aversion model.

2. If the individual decides to work zero hours, we assume that he will apply for DI. We have dropped individual subscripts for the present. 
indirect utility will be $-\mathrm{V}\left(\mathrm{w}_{\mathrm{A}}, \mathrm{y}_{\mathrm{A}}\right)^{-\Theta} \theta=-\mathrm{V}_{\mathrm{A}}^{-\Theta}, \theta .^{+}$Given 8 probability $\mathrm{p}$ of being accepted, the action taken by the individual is then determined by

$$
-V_{n}^{-\theta} / \theta-\left[p\left(-U_{0}\right)^{-\theta / \theta} / \theta+(1-p)\left(-V_{A}\right)^{-\theta / \theta} / \theta\right] 0 .
$$

If equation (6) is positive expected utility is maximized by not applying.

We now consider the stochastic specification of the model. Three sources of stochastic variation are allowed for. The first two are similar to a previous specification of Hausman (1980, 1981a). First, within the labor supply equation (2) we allow for different tastes for work. These taste differences are assumed to enter in an additive manner so we use the notation $S_{i}=Z_{i} \gamma+\tau_{i}$ where $E_{i}=0.2$ The second source of stochastic variation is the deviation between preferred and actual hours of work. We observe actual hours of work for those individuals who did not apply for DI. We let actual hours $h_{i}=h_{i}{ }^{*}+\eta_{i}$ where $E \eta_{i}=0$ and $E\left(S_{i} \eta_{i}\right)=0$. Therefore, the labor supply equation becomes

$$
h_{i}=\delta y_{i}+\alpha w_{i}+z_{i} \gamma+\varepsilon_{i}
$$

where $\varepsilon_{i}=\tau_{i}+\eta_{i}$. The stochastic components are separately identified here because of the non-linearity of the budget set, c.f. Hausman (1982).

To derive the likelihood function with these two sources of stochastic variation, we assume joint normality of $\tau_{i}$ and $\eta_{i}$ so that $\left(s_{i}, \eta_{i}\right) \sim \mathbb{N}\left(z_{i} \gamma, 0 ; \sigma_{\tau}^{2}, \sigma_{\eta}^{2}, 0\right)$. With this stochastic specification the decision to apply depends only on $S_{i}$ since the individual chooses with respect to

1. If the individual works zero hours, his direct utility function can be used.

2. Note we do not allow preference variation to enter through $\delta$ as in much of Hausman's previous work. Problems of uniqueness of choice regions occur in this case because of the presence of choice under uncertainty. Determination of all possible choice regions would complicate the problem considerably. 
preferred hours $h_{i}{ }^{*}$. Therefore, he does not apply if

(8) $\quad g\left(S_{i}, \theta\right)=\left(-U_{n}\right)^{-\theta / \theta} / \theta-\left[p\left(-U_{0}\right) / \theta+(1-p)\left(-U_{A}\right)^{-\theta / \theta / \theta j \geqslant 0 . ~}\right.$

Now it can be proven that a unique $S_{i}{ }^{*}$ exists so that for $S_{i} \geqslant S_{i}$ * the individual will not apply for DI. If the individual applies the contribution the likelihood function is

$$
\ell_{1 i}=\operatorname{pr}\left(S_{i}<S_{i}^{*}\right)=\Phi\left(\frac{S_{i}^{*} z_{i}{ }^{*}}{\sigma_{s}}\right)
$$

where $\Phi$ is the unit normal distribution. Here $S_{i}^{*}$ is the implicit solution to equation (8) which sets it equal to zero as a function of the estimated parameters and data for each individual. For an individual who does apply, we observe his hours of work. If these hours of work are greater than zero the contribution to the Iikelihood function is

$$
\text { (10) } \begin{aligned}
l_{2 i} & =\operatorname{pr}\left(S_{i}>S_{i}^{*} \bar{\varepsilon}_{i}\right) f\left(\bar{\varepsilon}_{i}\right) \\
& =1-\Phi\left(\frac{S_{i}^{*}-z_{i} \gamma-\left(\sigma_{s}^{2} / \sigma_{\varepsilon}^{2}\right) \bar{\varepsilon}_{i}}{\sigma_{s} \sigma_{\eta} / \sigma_{\varepsilon}}\right) \frac{1}{\sigma_{\varepsilon}} \Phi\left(\frac{\bar{\varepsilon}_{i}}{\sigma_{\varepsilon}}\right)
\end{aligned}
$$

where $\Phi$ is the unit normal density function and $\bar{\varepsilon}=h_{i}-\left(\alpha w_{n}+\delta y_{n}+z_{i} \gamma\right)$. However, the individual has zero observed hours of work if $\alpha_{n}+\delta y_{n}+S$ $<0$ or if $\eta$ is negative enough and for these individuals the contribution to the likelihood function takes the form

$$
\text { (11) } \begin{aligned}
\ell_{3 i} & =\operatorname{pr}\left(S_{i}>S_{i}^{*}, \varepsilon_{i}<\bar{\varepsilon}_{i}\right) \\
& =\Phi\left(\frac{\bar{\varepsilon}_{i}}{\sigma_{\varepsilon}}\right)-B\left(\frac{S_{i}^{*}-z_{i}^{\gamma}}{\sigma_{S}}, \frac{\bar{\varepsilon}_{i}}{\sigma_{\varepsilon}} ; \frac{\sigma_{s}}{\sigma_{\varepsilon}}\right)
\end{aligned}
$$

1. An appendix with this proof of uniqueness for the various models we consider is available upon request. 
where $B$ is the standard bivariate normal Iikezihood function. Therefore, the log likelihood function is

$$
I=\sum_{j=1}^{N_{1}} \log \ell_{1 j}+\sum_{j=1}^{N_{2}} \log \ell_{2 j}+\sum_{j=1}^{N_{3}} \log \ell_{3 j}
$$

where the first sum denotes applicants, the second sum denotes non-applicants with non-zero hours of work, and the third sum denotes non-applicants with zero hours of work.

Given the substantial effect on future income the decision to apply for DI will have, we might well expect variation in $\theta$ to be an additional important stochastic component of the model. The restriction that $\theta<-1$ is required to rule out risk loving behavior so we use a density $f(\Theta)$ which has support to the left of minus one. The distribution of $\theta$ for an individual is assumed independent of the other stochastic components of the model. The decision function of equation (8) now becomes a function $g\left(S_{i}, \theta_{i}\right)$ with variation in both $S_{i}$ and $\theta_{i}$ and the contributions to the likelihood function take the form

$$
\text { (13) } \tilde{l}_{1 i}=\int_{-\infty}^{1} \operatorname{pr}\left(S_{i}<S_{i}^{*} \mid \theta\right) f(\theta) d \theta
$$

Note that the value of $\theta$ determines the expected probability of application, but it does not affect preferred hours of work because it does not affect the ordinal properties of the utility function. The likelihood function for varying $\Theta$ takes the form

$$
\text { (14) } \tilde{I}=\sum_{j=1}^{N_{1}} \log \tilde{l}_{1 j}+\sum_{j=1}^{N_{2}} \log \tilde{l}_{2 j}+\sum_{j=1}^{N_{3}} \log \tilde{l}_{3 j}
$$

The BHHH algorithm was used along with a numerical integration subroutine. 
Computer requirements were significant given the presence of numerical integration.

We also included income taxes in the model. Only federal taxes were used and a progressive tax structure was used. Since the method of including taxes is similar to Hausman (1981a), we only briefly indicate the technique. For an individual who does not apply, as $S_{i}$ increases from $S_{i}{ }^{*}$ the individual's net wage falls as his denied hours put him into a higher tax bracket. His virtual wage is determined by $y$ and the tax system. The net,after tax, wage and virtual income then enter the labor supply function of equation (2). Let $S_{K}$ be the value of $S$ which marks the beginning of the tax segment or kink point on the budget set. Then the contributions to the likelihood function for a person who does not apply but has observed hours of work which exceed zero is

$$
\begin{aligned}
& \text { (15) } \tilde{\tilde{l}}_{2 i}=\sum_{\text {segments }} \operatorname{pr}\left(S_{k}<S<S_{k+1} \mid \varepsilon=\bar{\varepsilon}_{i}\right) \operatorname{pr}\left(\varepsilon=\bar{\varepsilon}_{i}\right) \\
& \text { for } \mathrm{S}_{\mathrm{k}} \geqslant \mathrm{S}_{i}{ }^{*} \\
& \begin{array}{l}
+\sum_{\text {kink points }} \operatorname{pr}\left(S_{k}<S<S_{k+1}\right) \text { pr }\left(\eta=\bar{\eta}_{i}\right) \\
\text { for } S_{k} \geqslant S *
\end{array} \\
& \left(\frac{\left(s_{k+1}-z_{i}^{\gamma}\right)-\left(\frac{\sigma_{s}^{2}}{\sigma_{\varepsilon}^{2}} \bar{\varepsilon}_{i}\right.}{\sigma_{s} \sigma_{\eta} / \sigma_{\varepsilon}}\right)-\Phi\left(\frac{s_{k}-z_{i}^{\gamma-\left(\frac{\sigma_{s}^{2}}{\sigma_{\varepsilon}^{2}}\right)}}{\sigma_{s} \sigma_{\eta} / \sigma_{\varepsilon}}\right) \frac{1}{\sigma_{\varepsilon}} \Phi\left(\frac{\bar{\sigma}_{i}}{\sigma_{\varepsilon}}\right) \\
& +\sum\left[\Phi\left(\frac{S_{k+1}-z_{i} \gamma}{\sigma_{s}}\right)-\Phi\left(\frac{S_{k}-z_{i} \gamma}{\sigma_{s}}\right)\right] \frac{1}{\sigma_{\eta}} \Phi\left(\frac{\bar{\eta}_{i}}{\sigma_{\eta}}\right)
\end{aligned}
$$

where $\bar{\eta}_{i}$ is the deviation of actual hours from kink point hours. For actual hours equal to zero $x_{3 i}$ is formed from $l_{3 i}$ in a similar manner. The form of 
$\ell_{1 i}$ remains the same. Variation in $\theta$ can also be included in the model with taxes.

We have specified three sets of models for DI applications in this section. One set holds $\theta$ constant in the population, one set allows $\theta$ to vary and one set includes taxes. In the next section, we estimate these models after we discuss how $p$, the probability of acceptance, and ${ }_{A}$, the market wage if rejected for $D I$, are determined.

1. Uniqueness of $S^{*}$ can also be proven in the model when taxes are present. 


\section{Model Estimation}

The data that will be used to derive empirical estimates are from the 1972 Survey of Disabled and Non-disabled Adults (SDNA). The samples of disabled and non-disabled civilian populations were selected separately from households in the 1970 Decennial Census 5-percent sample. Both samples were selected by area probability sampling methods to represent the noninstitutionalized civilian population aged 18-64 as of April 1970. Since the sample of persons selected in 1970 was two years older in 1972, persons aged 65-66 in 1972 were excluded in order to restrict the sample to those of working age.

In the 1972 survey individuals were asked detailed questions about their financial status, including amounts and sources of income, family situation, and kind of job currently or previously held. In addition, detailed current health and health-history questions were asked, including time of onset of health problems, current limitations in functional capacity, and extent to which health problems interfere with work. Because of the extensive information on health status, this data sample makes it possible to control fairly objectively for the effect of health on the labor/leisure choice instead of relying on self-reported disability status. The entire 1972 sample is composed of 8,633 adults who reported at least a slight disability and 9,364 non-disabled adults, including 1,745 persons who had recovered from previous disabilities.

An important problem occurs in selecting and defining the sample of actual or potential applicants over which to estimate the utility model. On the SDNA data tape, the survey data was matched with SSA entitlement records, which include such information as the date an individual filed for any kind 
of Social Security benefit, the date or dates he became entitled and tne type of benefit and benefit amounts received by him and his family. However, a record of filine for a Social Security benefit was only included for individuals who claimed and were confirmed to be receiving one, and not for individuals who may have applied but not been awarded benefits, whether for technical or medical reasons. Thus, it was quite straightforward to define the sample of individuals who were accepted applicants as individuals with SSA records of entitlement to DI benefits. In differentiating rejected applicants from non-applicants, however, it was necessary to rely on selfreported data.

The sample of rejected applicants was taken to be all individuals who satisfy the disability-insured requirement and who report applying for, but not receiving DI benefits and have no DI benefit entitlement record. The final sample consists of 4,214 men and 1,651 women. Of the men in the sample, 927 or 22 percent were DI receipients and 706 or 17 percent were rejected applicants (see Table 1).1 of the women in the sample, 319 or 19 percent were recipients and 351 or 21 percent were rejected applicants. Thus, approximately the same percentage of the men and women in the sample, 40 percent, had applied for benefits. Most of the DI recipients are over 55 and the percentage between the ages of 56 and 65 was about 55 percent for men and women, both white and non-whites in all categories tend to be younger than whites.

1. The sample of applicants consists of somewhat fewer DI recipients (57 percent) than were observed in the population. In 1972,60 percent of applications were granted and in previous years this percentage was slightly higher. Since the figure observed for the sample reflects the disposition of applications filed in all years since the program's inception, the higher mortality rate of DI recipients might account for the difference in the figures for the sample and the population. 
TABLE 1: Applicant Status of the Sample

\begin{tabular}{lccc}
\hline & Total & Men & women \\
DI Recipients & 1,246 & 927 & 319 \\
Rejected Applicants & 1,057 & 706 & 351 \\
Nonapplicants & $\underline{3,562}$ & $\underline{2,581}$ & 981 \\
Total & 5,865 & 4,214 & 1,651 \\
\hline
\end{tabular}

TABLE 2: Age and Race of the Applicant Groups, Male (numbers in parentheses are percentages)

\begin{tabular}{|c|c|c|c|c|}
\hline \multirow[b]{2}{*}{$\begin{array}{l}\text { DI Recipients (Total) } \\
\text { Under } 45 \\
45-55 \\
56-65 \\
\text { Over } 65\end{array}$} & \multicolumn{2}{|c|}{ White } & \multicolumn{2}{|c|}{ Nonwhite } \\
\hline & $\begin{array}{r}808 \\
101 \\
225 \\
479 \\
33\end{array}$ & $\begin{array}{r}(100) \\
(12) \\
(28) \\
(56) \\
(4)\end{array}$ & $\begin{array}{r}119 \\
17 \\
40 \\
60 \\
2\end{array}$ & $\begin{array}{r}(100) \\
(14) \\
(34) \\
(50) \\
(2)\end{array}$ \\
\hline $\begin{array}{l}\text { Rejected Applicants (Total) } \\
\text { Under } 45 \\
45-55 \\
56-65 \\
\text { Over } 65\end{array}$ & $\begin{array}{l}612 \\
104 \\
123 \\
278 \\
107\end{array}$ & $\begin{array}{l}(100) \\
(17) \\
(20) \\
(45) \\
(17)\end{array}$ & $\begin{array}{l}94 \\
16 \\
29 \\
39 \\
10\end{array}$ & $\begin{array}{l}(100) \\
(17) \\
(31) \\
(41) \\
(11)\end{array}$ \\
\hline $\begin{array}{l}\text { Nonapplicants (Total) } \\
\text { Under } 45 \\
45-55 \\
56-65 \\
\text { Over } 65\end{array}$ & $\begin{array}{r}2,396 \\
870 \\
800 \\
674 \\
52\end{array}$ & $\begin{array}{r}(100) \\
(36) \\
(33) \\
(28) \\
(2)\end{array}$ & $\begin{array}{r}185 \\
78 \\
54 \\
51 \\
2\end{array}$ & $\begin{array}{r}(100) \\
(42) \\
(29) \\
(28) \\
(1)\end{array}$ \\
\hline
\end{tabular}

1. Percentages may not add to 100 due to rounding. 
TABLE 3: Age and Race of the Applicant Groups, Pemale (numbers in parentheses are percentages) ${ }^{+}$

\begin{tabular}{|c|c|c|c|c|}
\hline \multirow[b]{2}{*}{$\begin{array}{l}\text { DI Recipients (Total) } \\
\text { Under } 45 \\
45-55 \\
56-65 \\
\text { Over } 65\end{array}$} & \multicolumn{2}{|c|}{ White } & \multicolumn{2}{|c|}{ Nonwhite } \\
\hline & $\begin{array}{r}315 \\
39 \\
97 \\
175 \\
4\end{array}$ & $\begin{array}{r}(100) \\
(12) \\
(31) \\
(56) \\
(1)\end{array}$ & $\begin{array}{r}56 \\
3 \\
19 \\
31 \\
3\end{array}$ & $\begin{array}{r}(100) \\
(5) \\
(34) \\
(55) \\
(5)\end{array}$ \\
\hline $\begin{array}{l}\text { Rejected Applicants (Total) } \\
\text { Under } 45 \\
45-55 \\
56-65 \\
\text { Over } 65\end{array}$ & $\begin{array}{r}350 \\
49 \\
82 \\
182 \\
37\end{array}$ & $\begin{array}{l}(100) \\
(14) \\
(23) \\
(52) \\
(11)\end{array}$ & $\begin{array}{r}60 \\
9 \\
14 \\
32 \\
5\end{array}$ & $\begin{array}{r}(100) \\
(15) \\
(23) \\
(53) \\
(8)\end{array}$ \\
\hline $\begin{array}{l}\text { Nonapplicants (Total) } \\
\text { Under } 45 \\
45-55 \\
56-65 \\
\text { Over } 65\end{array}$ & $\begin{array}{r}971 \\
348 \\
310 \\
279 \\
34\end{array}$ & $\begin{array}{r}(100) \\
(36) \\
(32) \\
(29) \\
(4)\end{array}$ & $\begin{array}{r}163 \\
78 \\
48 \\
34 \\
3\end{array}$ & $\begin{array}{r}(100) \\
(48) \\
(29) \\
(21) \\
(2)\end{array}$ \\
\hline
\end{tabular}

1. Percentages may not add to 100 due to rounding.

TABLE 4: Year of Entitlement to Benefits for DI Recipients (numbers in parentheses are percentages)

\begin{tabular}{lrrrrr}
\hline \multirow{2}{*}{ Year } & \multicolumn{2}{c}{ Male } & & \multicolumn{2}{c}{ Female } \\
\cline { 2 - 4 } Before 1960 & 15 & $(2)$ & & 5 & $(1)$ \\
$1960-1965$ & 284 & $(31)$ & & 137 & $(37)$ \\
$1966-1968$ & 241 & $(26)$ & & 73 & $(20)$ \\
$1969-1970$ & 278 & $(30)$ & & 122 & $(33)$ \\
$1971-1972$ & 109 & $(12)$ & 34 & $(9)$ \\
Total & 927 & $(100)$ & 371 & $(100)$
\end{tabular}


Table 4 shows the year of entitlement for DI recipients. Very few recipients had been entitled before 1960 which is not surprising since the program was fairly small in early years.

One of the major problems faced by empirical investigators of the behavior of disabled individuals is the absence of an objective measure of physical and emotional impairment. Most studies have been forced to rely on individuals' self-reported disability status to measure the extent to which their health problems or functional limitations interfer with their ability to perform duties required by jobs for which they have been or could be trained. Self-reported measures, however, may be biased by an individual's desire to justify not being employed, as well as by the fact that a question about whether someone is disabled may be interpreted in different ways by different individuals. Ideally, one would like to have an objective measure, such as a doctor's medical and psychiatric evaluetion, to control properly for the effect that phrsical or emotional impaiment, as opposed to attitudinal factors, has on an individual's labor force behavior and willingness to apply for benefits from earnings-replacement programs. For large cross-sectional deta sources, however, this kind of information has not been collected and it is probably prohibitively expensive to do so. Thus, we are forced to rely on self-reported information.

The survey data we are using has gone farther than any other currently available data source to collect the kind of objective information, albeit self-reported, necessary to permit the impact of the economic variables that are of principal interest to be measured. Several different kinds of questions were posed to survey respondents: their physical ailments or symptoms, such as pain and weakness; their specific disabling health conditions, such as cancer or heart trouble; and the extent to which their 
mobility is impaired. In ail, there are about 75 different dichotomous variables that might provide explanatory power in a study of the decision to apply for $D I$ benefits, and it would be impossible to include them all. Thus, these 75 variables must be reduced to a few variables that represent accurately the factors that are important in the application decision.

Three general approaches to the development of a set of health variables to be included in the analysis of the application decision suggest themselves. First, on an a priori basis a subset of the binary variables could be chosen. For example, it seems reasonable that restrictions in motor capacities, such as walking, standing and reaching, might be objective indications of health status. The inclusion of responses to the nine questions on motor capacity might be sufficient to represent all the health factors that influence an individual's work capability. For example, it is not necessarily important to know whether an individual has multiple scierosis or has had a leg amputated in order to determine whether he will have difficulty performing certain job activities. The important factor is whether he can walk or use the stairs if these activities are required for the performance of his current or a potential job. Thus, if the set of motor capacity questions were sufficiently exhaustive and accurate, there should be no increase in information on work capability and application probability from including the responses to questions on specific disabling health conditions.

While the same problem of self-justification arises in using the answers to these mobility questions as with the answers to the questions about whether the individual has a disability that interferes with his work, the questions are less likely to receive biased responses because they are specific. Moreover, the mobility questions were originally posed in the 
followine way: "Do you have any difficulty performin any of the activities on this card?" The nine mobility factors were presented on cards and the individual was asked whether he had difficulty or was completely incapable of performing the activity. No allusion was made to whether the inability to perform a job, that is, whether the individual considered himself to have a work disability because of the mobility impairment. Thus, it is less likely to that an individual who was not working would seek to justify his nonparticipation by falsifying these responses. In addition, the questions about health conditions were asked before the questions concerning work limitations. In addition to the mobility questions, seven questions on physical ailments, such as pain and weakness, eight questions ostensively on the physical environment, and three questions on hearing, sight and speaking difficulty were asked. The responses to whichever subgroup or subgroups of these questions are judged most relevant for determining the impact of poor health on the application decision should be included.

A second possible way to include the health variables would be to weigh the responses to the individual mobility, physical ailment, environmental sensitivity and sensory questions with predetermined weights, combining them into a small number of variables that index the degree to which the individual's impairments limit his ability to work. We have used governmentprogram set of weights to combine the responses, similar to the weights used by workmen's compensation program to determine the extent of disability and hence the number of weeks of benefits to which the individual should be entitled. These weights have an advantage over other methods in that they are theoretically justifiable on the basis of physicians' evaluations of the extent to which an individual requires the use of various parts of the body 
to perform his job. However, a certain amount of investigator juagement is still required in order to translate the answers to the questions asked in the SDNA into the workmen's compensation formulas. A third method to include the health variables is to use a statistical method to determine a weighting function. We have used the method of principal components to do so. All three methods are utilized in the empirical models.

In the utility maximization and probability of acceptance equations, we have used two weighted health variables, the first principal component of the responses to nine questions on individuals' functional limitations and index constructed using weights derived from the workmen's compensation (WC) program. The principal component variable (FNCTN) combined responses to yes/no questions about whether an individual had difficulty performing functions such as lifting, stooping, standing and reading. To help interpret the results, we note that its mean in our sample used to estimate the acceptance equation's 1.8 with a minimum of zero and a maximum of about 5 . The basis for the WC-based health variable is described in a paper by Burfield.1 His health variable, which he calls the functional limitations scale (FLS), is based on the American Medical Association's Guide to the Evaluation of Permanent Impairment, ${ }^{2}$ in which each body function is assigned a percentage of the whole body, and total body impairment is calculated based on the combined effect of the impairments of the various functions. Since the medical information needed to apply the AMA criteria is not available from Burfield's data base, the principles of the AMA evaluation procedure

1. Brad Burfield, "A Scale for Measuring Functional Limitations," Health Studies Program Working Paper No. 26, Syracuse University, April 1978.

2. American Medical Association, Guides to the Evaluation of Permanent Impairment, 1977. 
were apflied to the symptoms and functional limitations reported by survey respondents. In addition, information on specific medical conditions was incorporated when useful. The FLS index ranges from zero to 100.

Figure 2 shows the cumulative proportions for DI recipients, rejected applicants and nonapplicants in the sample by FLS groupings. As was expected, the chart shows that DI recipients tend to be more severely impaired than either rejected applicants or nonapplicants, and that rejected applicant;s are generally more impaired than nonapplicants. However, a significant proportion of DI recipients, about 10 percent, are less than 10 percent impaired which on a priori grounds seems too small to warrant their being granted DI benefits. The criteria for less than 10 percent disability are very weak. The individual responds only that he has breathing problems or has difficulty handling or lifting light objects. Thus it is somewhat surprising that any of the individuals in this category are DI recipients. There are two FIS values at which a considerable clustering of the sample appears -- 10 percent and 85 percent. An individual with a 10 percent disability responds only that his activities are limited without specifying which ones, or that he has breathing difficulty and difficulty lifting heavy objects or using stairs. These criteria are fairly broad and could be indicative of an enormous range of health problems. The clustering at 85 percent impairment occurs because blindness is rated as an 85 percent impairment and a large portion of the sample reports blindness and no other limitation. The relatively large number of applicants, both accepted and rejected, with greater than 85 percent impairment reflects the fact that many blind individuals also have other health problems.

In evaluating the expected utility of being a DI applicant, an individual assesses his probability of being accepted to the program if he applies. We assume that the information he uses to evaluate his chance of 
IMULATIVE

'ROPORIION

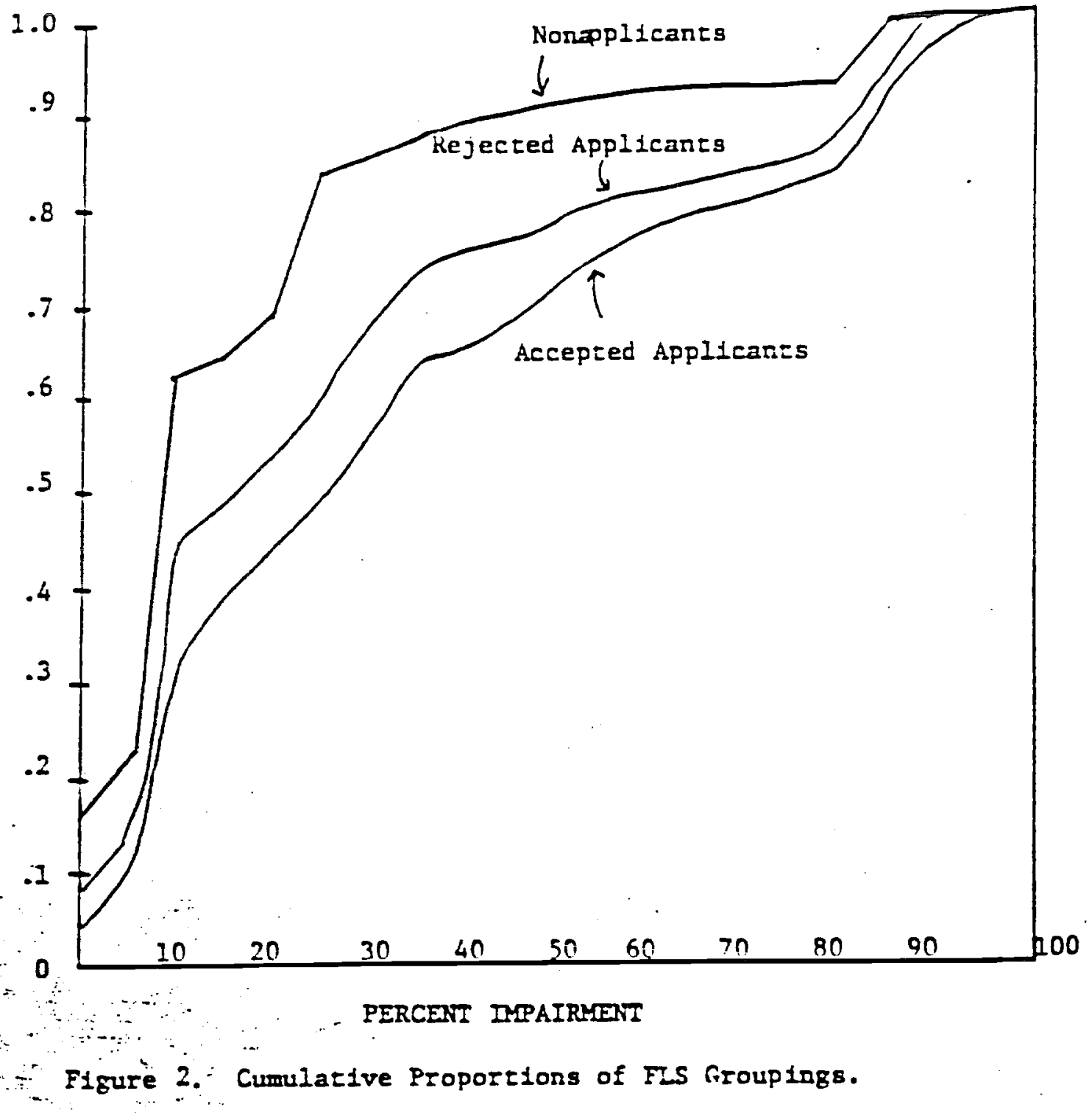


being eligible is the same information used by the SSA in arriving at eligibility decisions, and that the individual forms an unbiased estimate of his actual chances of being granted benefits. One reason to expect tinis to be true is that an individual interested in applying for DI benefits will engage in preliminary discussions with employees in the state SSA office, and he is likely to be informed at that time, while information to support his application is being gathered, of the probability that his application will be successful.

The equation estimated to predict the probability then an individual will be granted DI benefits assumes that there is no sample selection bias, i.e., that the sample of actual applicants used to estimate the equation does not differ from the population of applicants and non applicants to which it is being applied. This assumption seems reasonable since the statutory and actual criteria used by the Social Security Administration involve observable characteristics that can be quantified in both applicants and nonapplicents. In addition to health, the DI program regulations specify that eaucational and vocational factors should be considered in decisions on whether an individual's disability is sufficiently severe to warrant granting him DI benefits. Since prospects for retraining someone decline as he grows older, the probability of acceptance should increase with age. While nothing in the disability evaluation regulations would suggest that marital status or sex should be significant, these two variables might be taken into account and we decided to test their influence. 
TABLE 5. The Probability of Being Granted DI Benefits

\begin{tabular}{|c|c|c|c|}
\hline Variable $^{1}$ & Mean & $\begin{array}{c}\text { Probit } \\
\text { Coefficient } \\
\end{array}$ & $\begin{array}{l}\text { Asymptotic } \\
\text { Standard Error } \\
\end{array}$ \\
\hline $\begin{array}{l}\text { CONSTANT } \\
\text { AGEAPPS }\end{array}$ & $\begin{array}{l}1.0 \\
5.35\end{array}$ & $\begin{array}{r}.275 \\
-.006\end{array}$ & $\begin{array}{l}.229 \\
.004\end{array}$ \\
\hline AGE SQUARED & 132.9 & -.0019 & .0003 \\
\hline FLS CODE & 33.8 & .0013 & .0012 \\
\hline FIRST PRINCIPAL COMPONENT & 1.80 & .292 & .039 \\
\hline $\begin{array}{l}\text { PAIN } \\
\text { FAINT }\end{array}$ & $\begin{array}{l}.70 \\
.38\end{array}$ & $\begin{array}{l}.024 \\
.080\end{array}$ & $\begin{array}{l}.078 \\
.072\end{array}$ \\
\hline MOBDOORS & .64 & .197 & .148 \\
\hline ACCIDENT & .31 & -.062 & .074 \\
\hline MENTAL & .06 & .618 & .156 \\
\hline NERVES & .19 & .280 & .087 \\
\hline RESPIRATORY & .34 & .008 & .071 \\
\hline EDUCATION & 8.5 & -.009 & .009 \\
\hline MARRIED & .94 & -.379 & .156 \\
\hline NO. OF CEIIDREN & .68 & -.041 & .027 \\
\hline W & .87 & .036 & .103 \\
\hline HOME VALUE & 42.0 & .002 & .0008 \\
\hline ASSEIS & 28.5 & -.0006 & .0004 \\
\hline OTHER INCOME & 3.76 & .00009 & .0002 \\
\hline \multicolumn{4}{|c|}{$\begin{array}{l}\text { Other variables included: Dummy variables } \\
\text { for region and for rural residence. }\end{array}$} \\
\hline $\begin{array}{l}\text { Log of Likelihood Function } \\
\text { Percentage of Sample Accep } \\
\text { Number of Observations }\end{array}$ & ted & $\begin{array}{l}000 \cdot 2 \\
50.2 \\
475\end{array}$ & \\
\hline
\end{tabular}

${ }^{1}$ For definitions of variables, see Table $5 \mathrm{~A}$ which follows. 
Table 5A. Definition of Variables

AGEAPPS: Age at time of survey (1972) - 50

FLS CODE: FLS health index. Constructed from Workman's Compensation Formulae.

FIRST PRINCIPAL COMPONENT: First principal component of 9 functional limitation dummies which have value 1 if the individual's functional ability is impaired, O otherwise.

PAIN: Dummy variable with value 1 if individual frequently feels pain, 0 otherwise.

FAINT: Dummy variable with value 1 if individual can get around outdoors without help, 0 otherwise.

MOBDOORS: Dummy variable with value 1 if the individual can use doors without help.

ACCIDENT: Dummy variable with value 1 if individual's condition is caused by accident, 0 otherwise.

MENTAL: Dummy variable with value 1 if individual's health condition involves illness or retardation, 0 otherwise.

NERVES: Irammy variable with value $\hat{i}$ if individual has a nervous condition, 0 otherwise.

RESPIRATORY: Dummy variable with value 1 if individual has a health condition, such as emphysema, that involves breathing, 0 otherwise.

EDUCATION: Hizhest grade completed.

REGION 1: Dummy variable with value 1 if lives in the northeast, 0 otherwise.

REGION 2: Dummy variable with value 1 if lives in the northcentral, 0 otherwise.

REGION 3: Duminy variable with value 1 if lives in the south, 0 otherwise.

NOTMAR: Dummy variable with value 1 if the individuel is not married.

RACE: Dummy variable with value 1 if individual is nonwhite.

RURB: Dummy variable $=1$ if lives in rural area or small city, 0 otherwise. 
Table 5 shows the estimated probability of acceptance equation for a sample of 1475 men less than age 50 who applied in our sample. 1 we chose to estimate our model on this group of individuals so that interactions with the Social Security Retirement program are not a major factor. A more complex model would be required to account jointly for the DI program and ketirement program.

The functional limitations index constructed from the first principal component is extemely significant while the FLS health index only has a small additional effort. At the mean of the data the effect of the FLS index is less than $10 \%$ of the effect of the alternative index. These two indices were developed to measure the same factor, namely, an individual's ability to perform the activities that are necessary to hold a job or take care of himself. The FiS index, while it is a more complex and comprehensive measure, turned out to be only weakly correlated with the likelihood of being an applicant and to have limited explanatory power when the funtional limitations index is included. Other health condition measures added some explanatory power, in particular the ability to go out of doors without help and having a mental illness or nervous condition.

Two of the important factors in a disabled individual's decision whether to apply for DI are his expected earnings if he does not apply and his expected earnings if he applies and is rejected. Unfortunately, at least one of these variables is missing for each member of the sample. If an

1. If a rejected applicant's probability of acceptance is lower than that of someone applying for the first time, some bias could be introduced in the empirical work if the probability of acceptance does not include a variable that accounts for denial of a previous application. Unfortunately, the probability of acceptance equation does not include such a variable because the data tape did not provide enough information to ascertain the existence or disposition of previous applications. 
individual never applied and is currently working, his current earnings are given but there is no information on what his earnings would have been if he had applied and been rejected. If an individual applied and was rejected and is working, we have his "rejected applicant" wage but no information about his "nonapplicant" earnings. If the individual is receiving DI benefits, no information about either relevant earnings variable is given. Thus, it was necessary to input at least one wage variable for each member of the sample.

To impute the missing wage variables a reduced form specification is estimated. This $\log$ wage equation is used then to determine the decrease in a person's wage if he applies for DI and is turned down so he must reenter the labor force. We initially included two sample selection variables, but neither variable turned out to be important. The first variable was for the probability of applying while the second variable was for the probability of being accepted. The probit equation for the probability of being accepted is derived from Table 5. However, the probability model for applying was a reduced form of the structural utility model which is estimated subsequently. Efficient estimation would have required simultaneous estimation of the entire wage and utility model. We decided to forego this added computational complexity, especially since we did not find evidence of sample selection effects in the estimated wage equation. 
TABLE 6. Log Wage Equation for Males

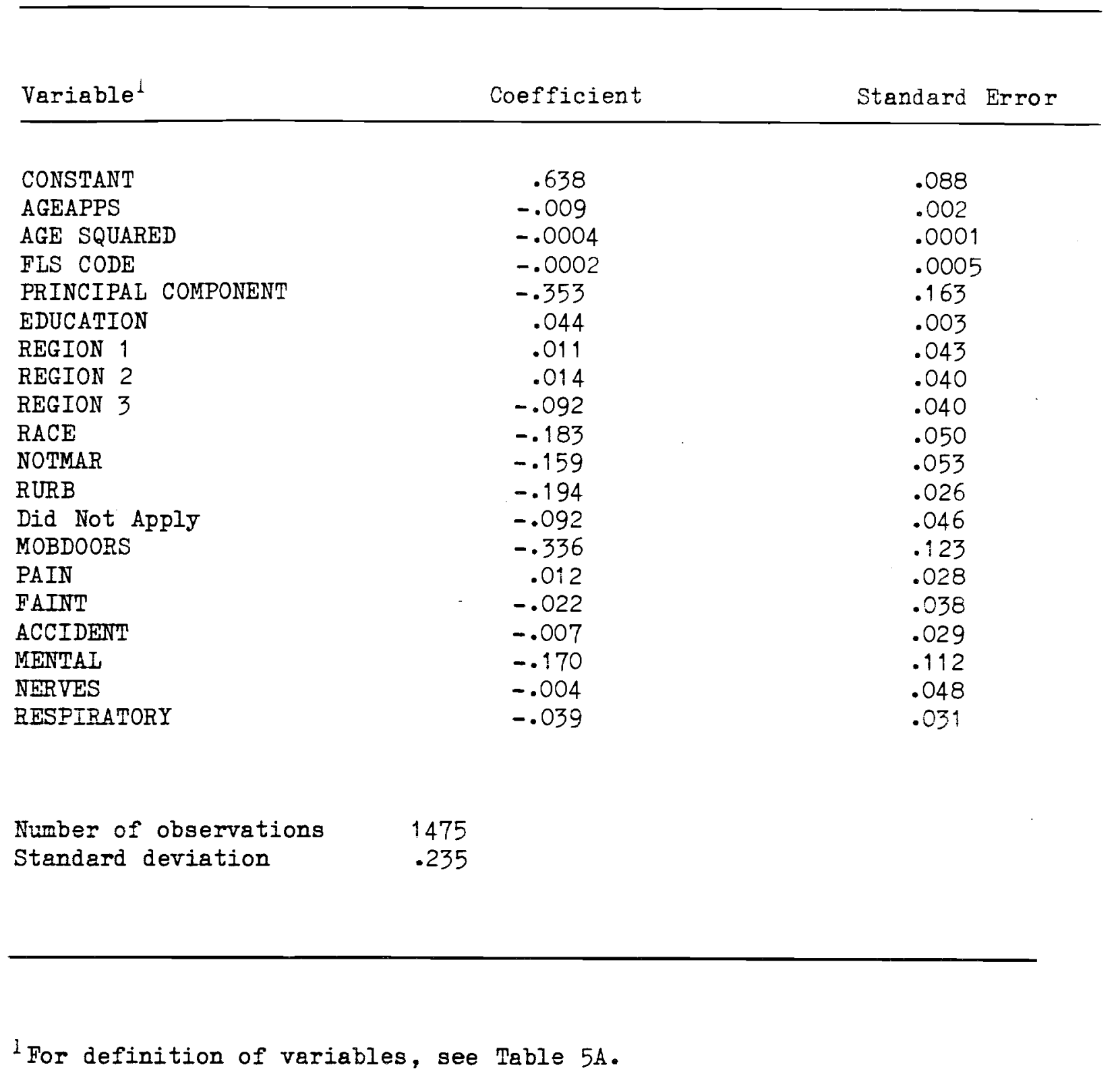


The results of estimating the wage equation for the sample of men are shown in Table 6. Marital status and amount of education are positively related to wages, while health, residence in the south, being non-white and being unmarried are negatively related. Note the large effect of health on the wage. A person with the mean health characteristics in the sample has a wage $64.2 \%$ lower than a healthy individual with otherwise identical characteristics. Thus, in principle, health has both an important direct effect on labor supply and an indirect effect because of the effect of health on the wage. The most important coefficient for use in the subsequent estimation is the coefficient for individuals who did not apply. It is entimated to be -.092. The estimate implies that an individual who applied but is rejected has a wage of exp- $(.092)=.912$ lower than a nonapplicant. We use this estimate to determine the ratio for $w_{n}$ and $w_{a}$, the wages of nonapplicants and applicants, respectively. ${ }^{1}$

We now proceed to estimate the combined probability of application and labor supply model of the last section. We divided the sample into men younger than age 50 and men age 50 and over. We present estimates here only for the younger group. The sample is restricted to applicants who applied for DI between 1967 and 1971 as well as those individuals who did not apply • Therefore, our results should be indicative of the situation in the early $1970^{\prime} \mathrm{s}$ in the DI program.

For non applicants, the comparison of utilities was made as of the end of 1971. For applicants, the estimated wage was deflated to the value in the

1. An earlier version of the paper estimated the ratio to be .51 rather than .91. However, this estimate arose from an error between earnings and wages. While earnings do decrease by about 50\%, most of this decrease is due to fewer hours of work. 
year in which the individual applied, usine the ratio of average hourly wages in 1971 and year of application. Earnings histories, reported year of application for rejected applicants, and the Social Security Administration benefits formula were used to calculate DI benefits for those individuals in the sample who were not receiving DI benefits. For nonapplicants, the benefit the individual would have been entitled to in 1971 was imputed. Adjustments were made for dependent children's and spouses' benefits. The model from equation (8) of the last section determines the decision on whether an individual applies. The individual compares the utility achieved if he does not apply with the expected value of the uncertain outcomes if he does apply. To make this latter calculation he uses the probability of acceptance and decline in his wage if he applies but is rejected. Both the probability of acceptance and the decline in the wage are derived fron the estimates in Tables 5 and 6 . The parameters of the model can be most easily interpreted with respect to the labor supply functior of equation (7) and the parameter which is the parameter which measures the degree of risk aversion. We present the results in Table 7. 


\section{TABLE 7: Estimates of Application and Labor Supply Model ${ }^{1}$}

Variable

1. Non-labor income (virtual): $\delta$

2. Wage $\alpha$

3. Constant

4. Education

5. Number of Children

6. Principal Component for Healtin

7. FLS Code for Health

8. Not Married

9. Non White

10. Age

11. Accident

12. Respiratory Distress

13. Mental Problem

14. Pain

15. Faint
$\underline{\Theta \text { Fixed }}$

$-.122$

$(.024)$

.023

$(.005)$

1.51

(.133)

.199

(.059)

$-.021$

(.012)

-.257
$(.023)$

$-.0021$

$(.0007)$

$-.251$

$(.059)$

$-.397$

(.059)

.037

$(.023)$

.013

(.040)

$-.076$

(.045)

$-.486$

(.096)

$-.086$

(.045)

$-.216$ $\theta$ Varying

$-.121$

(.064)

.024

(.059)

1.49

(.385)

.196

$(.086)$

$-.029$

$(.030)$

$-.265$

(.071)

$-.0020$

(.0025)

$-.249$

$(.166)$

$-.395$

(.171)

.030

$(.076)$

.011

$(.024)$

$-.076$

$(.046)$

$-.466$

(.099)

$-.088$

(.046)

$-.218$

(.051) 
TABLE 7 - Continued

$\begin{array}{cc}-.267 & -.269 \\ (.099) & (.102) \\ -.303 & -.303 \\ (.058) & (.059) \\ .528 & .548 \\ (.024) & (.078) \\ .475 & .472 \\ (.024) & (.151) \\ -4.48 & -4.50 \\ (1.14) & (.126) \\ - & .170 \\ -476.8 & (.012) \\ 1411 & -450.8\end{array}$

16. Mobility through doors

17. Nervous condition

18. $\sigma_{\mathrm{s}}$

$-.267$

$(.099)$

\section{7 - Continued}

19. $\sigma_{\eta}$

20. Theta or Mean Risk Aversion Parameter for Normal Dist.

21. Standard Derivation for Normal Distribution for Risk Aversion

Log Likelihood

Number of observations

1411

1. Hours are measured in $1000^{\prime} \mathrm{s}$ as is income. Asymptotic standard errors are given in parenthesis. For variable definitions see page 32, Table $5 \mathrm{~A}$. 
The left hand column has the estimates with income taxes and social security where $\theta$, the parameter of risk aversion, is assumed constant in the population. The estimates of the underlying labor supply model of equation (2) seem quite good. The effect of nonlabor income is similar to Hausman (1981a), while the direct effect of the wage on labor supply is quite small, consistent with previous studies of male labor supply. Thus, individuals in the sample behave much as other prime age males have been estimated to behave except for the important difference which health creates. The health coefficients have a quite large effect on the labor supply equation and on the probability of application since the probability of application rises as work becomes less attractive. Note that at the mean value of the principal component variable for health, an individual's desired hours of work decrease by 462 hours per year compared to a person with no disability. The other health index, the FLS code at its mean leads to a further decrease of 71 hours per year. Also, particular health problems such as mental problems, lack of mobility through doors, and a nervous condition each lead to a further decrease in desired hours of work exceeding 250 hours per year. Age seems to have little effect which might be expected given our sample of younger men. The components of variance indicate the importance of variation in tastes in determining work behavior which is a finding also present in previous studies of male labor force behavior.

The other part of the model besides the labor supply specification is the application model which incorporates individual's attitudes towards risk. Here, the key parameter is $\theta$ which is the coefficient of risk aversion in our constant relative risk aversion specification of equation (3). The coefficient of risk aversion, $\theta$, is estimated to be -4.5 which indicates a substantial degree of risk aversion. The estimate of $\theta$ is quite good, but 
the estimate is very sensitive to the ratio $k_{A} / k_{N}$, the decrease in the market wage if an individual applied for DI and was rejected. This ratio along with health status are tine major determinants of the application decision. Note that health status has an importance influence on the desired hours of work as discussed above as well as an additional important influence through the probability of acceptance model in Table 5 .

Variation in $\theta$ is now included by permitting the parameter of risk aversion to vary in the population according to a normal distribution. Equations (13) and (14) demonstrate the method used to allow $\Theta$ to vary. 1

As can be seen in Table 7 , the coefficients of the parameters in the model are extremely close to the case when $\theta$ is held constant. However, the value of the maximized likelihood function does increase by 21.0 which indicates the presence of dispersion in the population. The mean parameter of the normal distribution is estimated to be -4.50 which is extremely close to the model estimated without variation. The findings indicate a statistically significant amount of dispersion in risk aversion in the population although the amount of variation is not large with the standard deviation of the distribution of risk aversion estimated to be .170 . However, the interpretation of our results must be Iimited due to the assumed functional form of the distribution for theta.

1. This model proved quite difficult to estimate. The accuracy of the estimated asymptotic standard errors is especially doubtful because of the use of numerical integration in the calculations. 
We now use estimates from Table $;$ to simulate what changes in the probability of acceptance would do to the number of applicants for DI. In our sample .079 of all individuals have applied for DI. Our model predicts that .073 would apply which is quite close given that the model is basically one of labor supply under uncertainty. For each individual we now alter the probability of acceptance either upward or downward by a given amount. We then compute the probabilities across individuals and take an average to determine the effect of changes in the probability of acceptance. The results of the simulation are given in Table 8 . The results in Table 8 indicate that a change in the probability has an important effect, although it is not particularly large. For instance, if the probability of acceptance is multiplied by .7 the predicted number of applicants falls by about $6.8 \%$. 
TABLE 8: Simulations for Changes in Probability of Acceptance

\begin{tabular}{cc} 
Probability Multiplied by & Probability of Application \\
\hline 1.0 & $\frac{\theta=-4.48}{.073}$ \\
.9 & .072 \\
.8 & .070 \\
.7 & .068 \\
.6 & .066 \\
.5 & .063 \\
.3 & .053 \\
.1 & .029 \\
1.1 & .074 \\
1.2 & .075 \\
1.3 & .076
\end{tabular}


If the probability of acceptance falls by .5 wrich is approximately the change from 1975 to 1981, the model predicts that applications will fall by about $13.7 \%$ which is approximately what has been observed in the period. Note that a $14 \%$ decrease is about half way between $8 \%$ and $19 \%$ which we calculated to be the bounds of the actual decline in DI applications over the period. Therefore, the model which is fit on cross section data seems to predict the subsequent times series results quite well. However, we found that other specifications could also fit the subsequent time series results almost equally well.

In our last simulation we consider the effect on applications of a fall in DI benefits which may occur due to the change in COLA provisions in Social Security given the 1982 legislation and the proposed 1985 legislation. Results are given in Table 9 . Here we note that applications are sensitive to the benefits. If benefits were to decrease to .8 of the level used in the model we find that applications would decrease by $21.9 \%$. Therefore, our estimates indicate that the applications decision is a good deal more sensitive to benefit levels than to the probability of acceptance. While it is difficult to decide whether the increase in DI benefits in the 1970's 'explains' a large proportion of the decrease in male labor force participation of prime age males, the benefit level does have a significant and sizeable effect on the decision to apply for DI. I

1. Havemann and Wolfe (1984) conclude that the benefit level has only a small effect on DI in contrast to the findings of earlier research. 
TABLE 11: Probability of Application with Benefits Changed

Social Security Benefit multiplied by:

$$
\begin{aligned}
& 1.2 \\
& 1.1 \\
& 1.0 \\
& 0.9 \\
& 0.8
\end{aligned}
$$

Average probability of applying

$$
\theta=-4.48
$$


REFERENCES

Halpern, J. (1981), Determinants of Applications for Social Security Insurance, unpublished MIT Ph.D thesis.

Hausman, J. (1980), "The Effect of Wages, Taxes, and Fixed Costs on Womens Labor Force Participation", Journal of Public Economies, 14.

Hausman, J. (1981a), "Labor Supply", in H. Aaron and J. Pechman, How Taxes Affect Economic Behavior (Washington: Brookings)

Hausman, J. (1981b), "Exact Consumers Surplus and Deadweipht Loss", American Economic Review, 71 .

Hausman (1982), "The Econometrics of Nonlinear Budget Sets", mimeo.

Havemann, R. and G. wolfe (1984), Disability Transfers and Early Retirement, Journal of Public Economics, 24.

Lando M. et. al. (1982), "Recent Trends in the Social Security Disability Insurance Frogram", Social Security Bulletin, 45.

Machina M. (1983) "The Economic Theory of Individual Behavior Toward Risk: Theory, Evidence, and New Directions", mimeo.

Mashaw, J. (1983), Bureaucratic Justice, New Haven, Yale University Press. 